\title{
QUAL O PREÇO DE SER MENINA? IMPLICAÇÕES DAS EXPECTATIVAS CORPORAIS
}

\author{
Maria Simone Schwengber \\ Universidade Regional do Noroeste do Estado do Rio Grande do Sul, Ijui, Rio \\ Grande do Sul, Brasil
}

\begin{abstract}
Resumo
Este artigo, inspirado no campo dos estudos de gênero, analisa as estratégias voltadas para a normalização e o controle das expectativas corporais esportivas de meninas e de meninos. A proposta é responder a seguinte questão: quem e o que se fala sobre as expectativas corporais esportivas das meninas e dos meninos? Para essa discussão, selecionei uma matéria publicada na revista Pais \& Filhos. Neste momento de análise, destaco que os modos como a mãe orienta a educação de meninos e meninas evidenciam o processo discursivo de configuração de identidades pautado por modelos pedagógicos bastante tradicionais (menina não pode jogar) e por conceitos que parecem ser propagadores de desinvestimento da feminização esportiva.
\end{abstract}

Palavras-chave: Práticas Corporais. Práticas Esportivas. Gênero. Família.

\section{Introdução}

$\mathrm{E}$ ste artigo, inspirado no campo dos estudos de gênero, trata das relações de gênero e poder presentes nos processos de socialização de crianças na família e analisa as estratégias voltadas para a normalização e o controle das expectativas corporais esportivas de meninas e meninos. Busco ainda identificar a relação da família com as ações prescritas pelos discursos das práticas corporais e esportivas.

Lanço a seguinte pergunta de pesquisa: quem e o que se fala sobre as expectativas corporais das meninas e dos meninos? Para essa discussão, selecionei uma matéria da revista Pais \& Filhos. No contexto da mídia brasileira direcionada à família, ressalto a importância dessa publicação, tida como "a mais tradicional revista da família brasileira" (MIRA, 2001, p. 112). Observei as imagens que frequentemente integram os textos na revista não como peças ilustrativas, mas como práti- 
ca discursiva. Soares (2002) e Goellner (2003) ensinam que as imagens não são independentes, pois estão ligadas a determinados regimes de poder e movimentam significados, induzindo a que se vejam algumas coisas em detrimento de outras.

Procurei fazer neste artigo um exercício de problematização da categoria gênero, recorrendo a Meyer (2004), que destaca alguns pressupostos: assumir que as diferenças corporais entre meninas e meninos são construídas social, cultural e discursivamente; problematizar as relações de poder em que essas diferenças são produzidas, vividas; e operar com a pluralidade e a provisoriedade do viver e definir o gênero em diferentes tempos e lugares (neste caso, a família).

Vale destacar que a referência à expressão família não implica a consideração de que exista um modelo único e ideal. Entendo que existem diferentes configurações na definição de família em função das experiências e dos contextos culturais em que as famílias estão inseridas (FONSECA, 2000).

\section{Meninos, meninas e as expectativas corporais: implicações da fa- mília}

Ao refletir sobre as diferenças corporais de meninos e meninas no âmbito da mídia, é possível pensar, como mostra o diálogo abaixo, em uma pedagogia do gesto e da vontade, dos modos de ser menino e de ser menina, configurando-se, assim, uma "educação dos corpos" (GOELLNER, 2003). Entre as páginas 22 e 25 da edição de maio de 1982 da revista Pais \& Filhos, há um suposto diálogo entre um menino e uma menina carregado de expressões e gestos (indagações, caretas, piscar de olhos, sorriso desconfiado), de perguntas e reflexões, aproveitando o mote da pequena diferença (de)marcada pela mãe. O menino, bastante intrigado (mais do que a menina), faz reflexões curiosas acerca das orientações contraditórias da mãe. 


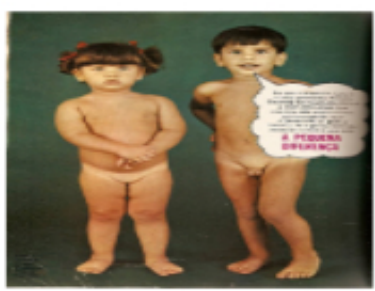

Menino: Eu sou Marcelo. Esta é minha priminha Renata. Ela está bronqueada porque a mãe dela disse que menina não pode brincar com a gente, que menino não é igual à menina. Aí, a gente resolveu descobrir onde é que está a pequena diferença.

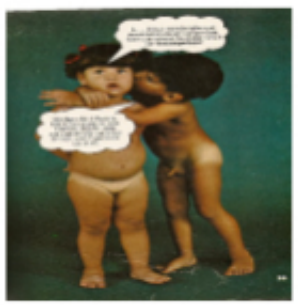

Menina: É... Mas mamãe falou que menina tem que ser comportada. Será que brincar de chutar a bola é ser descomportada?

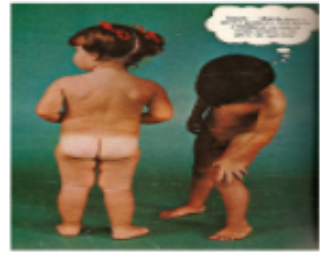

Menino: Não liga, não, ô Renata. Não é por causa de uma diferencinha de nada que a gente não vai poder brincar, ora! A gente dá um jeito. Menino: Gozado... Olhando daqui a gente é igualzinho. Será que se a mamãe me visse de costas também ia me proibir de jogar bola?

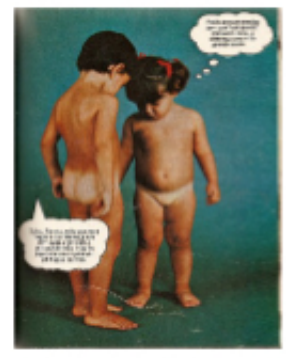

Menina: Então por que menina tem que ficar quieta? Pensando bem, a diferença nem é tão grande assim...

Menino: Sabe, Renata, acho que esse negócio da diferença não tem nada a ver com a brincadeira, não. A gente joga bola com o pé, e seu pé é igual ao meu.

Figura 1: Matéria "A pequena diferença", da revista Pais \& Filhos, v. 4, n. 9, p. 2225, mai. 1982.

Pensar a Prática, Goiânia, v. 15, n. 3, p. 551-820, jul./set. 2012 
É importante pensar, a partir desse diálogo, como a família (a mãe) age, como valoriza e nomeia determinados comportamentos (modos de ser) como sendo de meninas e de meninos, dando-lhes tratamento social diferenciado, de acordo com as expectativas corporais e segundo o gênero das crianças. Entendo que essas nomeações são fundamentais no processo de constituição de identidade de gênero. Definir-nos por ser homem ou mulher faz parte de um processo cultural. É nesse sentido e sob essa perspectiva conceitual que faz sentido compreender os sujeitos (as crianças) e as práticas educativas de gênero. É possível destacar, a partir desse diálogo, o quanto as referências ao gênero não são meras características oriundas da biologia do corpo - são construções sociais, históricas, datadas e localizadas aqui em um espaço, como no universo da família.

Gênero é uma categoria conceitual que traz à tona a compreensão de que ninguém nasce mulher/homem, menino/menina, e que essas condições são produzidas pela história e pela cultura. Não são fundadas apenas na ordem da natureza (corporal), sendo da ordem do vir a ser e do fazer, da produção. É "a civilização como um todo que produz" a posição de gênero (BEAUVOIR, 1980, p. 301). Para Butler (1999, p. 161), o processo de generificação torna-se dizível desde a vida intrauterina, lembrando que a:

[...] emergência recente de ecografias transforma uma criança, de um ser "neutro" em um "ele" ou em "ela": nessa nomeação, a garota torna-se uma garota, ela é trazida para o domínio da linguagem e do parentesco através da interpelação do gênero". Mas esse tornar-se garota não termina ali; pelo contrário, essa interpelação fundante é retirada por várias autoridades, e ao longo de vários intervalos de tempo, para reforçar ou contestar esse efeito naturalizado. A nomeação é, ao mesmo tempo, o estabelecimento de uma fronteira e também a inculpação repetida de uma norma.

Desse modo, pensar as questões de gênero, como diz Louro (1997, p. 127), é "pensar a educação de homens e mulheres, meninos e meninas para muito além dos limites que a temos pensado". É pensar que até mesmo o recém-concebido, a criança, "não é outra coisa senão aquilo que colocamos nele", como afirma Larrosa (2001, p. 187). Para 
Louro (1997, p. 112), a partir da declaração "é menino" ou "é menina", começa-se uma "espécie de viagem", instala-se um processo que, supostamente, deve seguir um determinado rumo e/ou uma direção. Constituímo-nos como sujeitos generificados desde muito cedo, desde o momento da concepção. São os rituais, as práticas educativas da cultura que permitem que essa constituição seja costurada.

Segundo Meyer (2004, p. 12), não podemos deixar de perceber que os processos que nos educam - na família e, neste caso, também na revista - "são conflituosos, instáveis e recheados de disputas e é no interior dessas disputas (...) que se constrói aquilo que reconhecemos como certo/errado, normalidade/desvio, nós/eles, homens/mulheres, meninos e meninas".

Observa-se, a partir do diálogo abaixo, que as crianças não sabem o que diferencia um menino de uma menina.

Menino: Gozado... Olhando daqui, a gente é igualzinho. Será que se a mamãe me visse de costas também ia me proibir de jogar bola?

(PAIS \& FILHOS, v. 4, n. 9, p. 22-25, maio 1982).

Como se vê, o corpo, a condição material (física) e as diferenças entre masculino e feminino parecem não ter importância para as crianças pequenas. Na realidade, são os adultos que demarcam, desde o início, a diferença dos corpos. No caso do diálogo, a mãe diz que menina que não pode brincar com menino, que menino não é igual à menina; para as crianças, é difícil de entender porque não podem brincar juntos e qual é essa diferença. É importante pensar o quanto o corpo representa justamente essa indissociabilidade entre natureza e cultura. Se, por um lado, há um patrimônio biológico universal que torna todos os humanos membros de uma mesma espécie, por outro, há construções educativas diferentes para meninos e meninas. Assim, o corpo torna os homens e as mulheres iguais, porém também os torna diferentes. Nessa afirmação, há algumas implicações.

Logo que as crianças nascem, cuida-se de nutrir seus inconscientes, primeiramente, com o modo como se comporta, com quais atividades uma menina e um menino devem se envolver. Como também se observa no diálogo, a mãe opta por um padrão de tratamento para cada gênero: menina tem que ser comportada, não chutar bola, não jogar futebol, ser passiva. Talvez essa mãe inconscientemente queira que a família mantenha os gostos e o estilo de vida (passivo) semelhantes 
aos dela. Para Daoilo (2004), geralmente se tem uma expectativa de o macho ser altivo, seguro, ativo, ágil; já sobre da menina paira uma névoa de delicadeza, passividade e cuidados.

Desse modo, destacamos a condição sobreposta, da figura masculina sob a feminina, e como as relações de gênero têm sido construídas a partir de binarismos, distinguindo, nesse caso, pelo discurso da mãe, o feminino e o masculino em ativo/passivo, forte/frágil, vulnerável/valente. As diferenças de gênero expressam-se, desde a infância, materialmente nos corpos e, os discursos presentes produzem verdades sobre os sujeitos, suas posições, e sobre seus corpos, suas habilidades (LOURO, 1997). Assim sendo, nesse caso, destacamos que a menina, na relação estabelecida entre os gêneros, é vista como o lado oposto ao primeiro elemento, o menino, o que pode (o mais forte da corda), e o segundo elemento, a menina, inferior ao primeiro (a corda arrebenta quase sempre do lado mais fraco). As forças parecem iguais, ou melhor, as condições parecem iguais, mas um lado vai sendo consumido pela força do outro lado e de repente a vida arrebenta.

Assim, a cultura - e incluo aqui a cultura familiar - produz determinadas identidades, como destaca Meyer (2004). O conceito de identidade de gênero apresenta íntimas conexões com a realidade social, pois essa identidade:

[...] não é algo que encontremos, ou que tenhamos de uma vez e para sempre. Identidade é um processo. As identidades sociais surgem em manifestações de discurso, pois, embora a identidade possa ser construída de diversas formas, ela é sempre construída no simbólico, ou seja, na linguagem, nos discursos (SILVA, 2002, p. 124).

A identidade de gênero constitui uma extensão da liberdade da condição humana, sendo instável, transitória e aberta à redefinição permanente. A identidade não é algo que exista a priori; ela é constituída (SILVA, 2002). A identidade não está ligada a ser, mas a estar, ou, mais especificamente, a representar. Sendo a identidade uma construção social e não um dado herdado biologicamente, ela se dá no âmbito das representações. Desse modo, as produções identitárias do bom menino ativo, da boa menina ativa e de quem pode ser esportista (ou não) são demarcadas em contextos específicos, como os familiares, como se vê no excerto abaixo: 
Menina: Pensando bem, a diferença não é tão grande assim...

Menino: A gente joga bola com o pé, e o seu pé é igual ao meu.

(PAIS \& FILHOS, v. 4, n. 9, p. 22-25, maio 1982).

Observando o diálogo com mais atenção, ainda podemos perceber que as crianças não se diferenciam corporalmente. $\mathrm{O}$ enunciado "o seu pé é igual ao meu" contribui para mostrar a relação de igualdade corporal entre meninos e meninas. Porém, quem coloca isso sob suspense é o adulto (feminino, a mãe), criando uma segmentação por gênero. Logo, já na família observa-se, nesse caso, que toda uma presença indutora de hábitos está a apoiar e a alimentar tal iniciativa nos modos de se relacionar com os esportes.

Sendo assim, questiono: Por que as mães sempre acham que menina não sabe jogar futegol? Rago (2000) ajuda-nos a entender que há uma "colonização da mulher", em que o modelo imaginário, "de feminilidade, de mulher passiva, recatada talvez constitua ainda peças mestras de um jogo de agenciamentos das "relações intrafamiliares". O corpo feminino é tornado visível em sua negatividade, no chamamento da mãe. De forma por vezes dolorosa, em rituais avaliativos constantes, as meninas são tidas como as que têm um corpo atrofiado, inadequado, sem tônus, sem jeito para o esporte. Aprendem, desde muito cedo, a olhar para seu corpo com desgosto e a conformar-se com ele. Del Priore (1997) destaca que talvez uma parte da história das mulheres passa também pela história daquelas palavras que as mulheres ouviram ser-lhes dirigidas, que a história das mulheres não é só delas, é também aquela da família, do trabalho, da mídia, da leitura. É a história de seu corpo, de sua sexualidade, da violência que sofreram e praticaram.

Observando as expressões discursivas da mãe no diálogo destacado pela revista, percebe-se que a condição da menina comportada que não joga futebol é construída pela mãe, que a coloca na posição de não saber jogar futebol. Essa é uma construção discursiva que a mãe coloca à menina - esta, em condição inferior - por meio da linguagem. Segundo Bordo (1980), o preconceito estigmatizante ${ }^{1}$ regula

1-Refiro-me ao estigma como uma marca social da pessoa na vida íntima, chegando muitas vezes a alterar a auto percepção do indivíduo. Erving Goffman (1988) diz que o estigma não é somente relacionado a um defeito físico, mas também a uma organização socialmente estereotipada, podendo esta afetar a identidade pessoal.

Pensar a Prática, Goiânia, v. 15, n. 3, p. 551-820, jul./set. 2012 
nossas vidas e nossos corpos, sendo muitas vezes passado por uma mulher, a própria mãe. Ela é também portadora dos preconceitos inerentes a uma cultura, colocando-nos diante de discursos e atitudes, no caso, menos ativas, e passando-nos o seu sentir-se desvalorizada corporalmente. Nesse contexto, podemos supor que a mãe (...) talvez revele inadvertidamente, num nível bem básico as memórias de (des)valia corporal no nível de um subconsciente que é ao mesmo tempo individual e coletivo (BORDO, 1980).

Nessas cenas do diálogo analisado, também é possível observar que, apesar de toda a bagagem de estereótipos da mãe, as crianças ainda encontram espaços para desafiar - sobretudo o menino, que ajuda a menina a reagir, questionando e não aceitando essa penitência. Sendo assim, as crianças resistem à pressão de determinadas expectativas corporais e encontram brechas no gerenciamento do dia a dia, criando estratégias.

Tornar-se homem ou tornar-se mulher, nos processos de socialização, dá-se de forma contínua, iniciando-se na família e sendo reforçado em outras instituições. Entendo esse processo de socialização como algo sempre incompleto, que ocorre ao longo da vida. Nesse processo longo e inacabado, distinguem-se duas fases: socialização primária e socialização secundária. A família é considerada como socialização primária, como contextos que se fazem sentir desde muito cedo numa atmosfera emocional, em aprendizagens iniciais. Melhor dizendo, a autopercepção corporal organiza-se durante a relação objetal, desde quando a criança nasce; sua relação com a mãe ou com pessoas que a cuidam é que será capaz de confirmar seu autoconhecimento corporal. Neto (2000) descreve que as outras instâncias de socialização, chamadas secundárias, são a escola, os grupos de pares, os meios de comunicação social. No entanto, destaco que essas instâncias não têm o mesmo peso no processo de socialização.

Infelizmente, a ideia de fracassos do corpo feminino se reproduz em contextos culturais, como os da escola, sobretudo nas aulas de educação física. Há um movimento chamado de feminização do magistério, e as imposições corporais e sociais muitas vezes entram num ciclo sem fim e repetem-se. Em algumas aulas de Educação Física, as meninas ainda são consideradas como estranhas, fora do lugar. Ao ser considerada o outro, a menina é marginalizada. Destaco a educação escolar, como espaço público (assim como outros espaços), como um caminho privilegiado para contrapor os estereótipos de gênero produ- 
zidos, no caso na família. Uma nova ordem passa pela superação de resquícios e apela para um posicionamento político. A análise crítica é um dos vetores que podem rasgar, fissurar as tramas dos discursos limitadores das condições femininas, sejam ela familiares, escolares ou outras.

\section{Conclusão: avançar é preciso}

Estamos no início de um milênio, momento importante para pensarmos de que forma as mulheres, as meninas, cada vez mais produtivas e ativas na vida social, desempenharão sua posição no universo esportivo. Hoje, os estudos de gênero nos dão a oportunidade de construir outra história das mulheres no esporte. É dessa forma que entendo que será possível desmistificar muitas definições que interpretam a diferença como sinônimo de fragilidade. Como nos lembra Goellner (2005, p. 4), "afinal, não podemos esquecer que, na sociedade contemporânea, o esporte é um palco privilegiado para a exposição de corpos que, ao exibirem-se e serem exibidos, educam outros corpos". Torçamos para que nos eduquem nomeando-nos como "Meninas de Ouro", pois, como nos ensinam as crianças do diálogo, "pensando bem, a diferença não é tão grande assim, a gente joga bola com o pé, e o seu pé é igual ao meu". Diante dessa perspectiva conceitual, conclui-se que se torna impossível falar de uma identidade de gênero (e de esporte) única e acabada, conforme considera Bauman (2005, p. 17):

Tornamo-nos conscientes de que o "pertencimento" e a "identidade" não têm a solidez de uma rocha, não são garantidos para toda a vida, são bastante negociáveis, e de que as decisões que o próprio indivíduo toma, os caminhos que percorre, a maneira como age - e a determinação de se manter firme a tudo isso são fatores cruciais tanto para o pertencimento como para a identidade. [...] a identidade só nos é revelada como algo a ser inventado, e não descoberto; como alvo de um esforço, um objetivo; como uma coisa que ainda se precisa construir a partir do zero ou escolher entre alternativas e, então, lutar por ela e protegê-la lutando ainda mais - mesmo que, para que essa luta seja vitoriosa, a verdade sobre a condição precária e eternamente inconclusa da identidade deva ser, e tenda a ser, suprimida e laboriosamente oculta. 


\title{
How much does it cost to be a girl? Implications of body expectations
}

\begin{abstract}
This paper, inspired by the field of gender studies, analyzes strategies directed towards the normalization and control of (sportive) body expressions of girls and boys. I have attempted to answer the following question: Who talks and what is said about "sportive" body expectations of girls and boys? The methodology employed has followed the Foucauldian analysis perspective. For this discussion, I have selected reports taken from Pais \& Filhos magazine. I can highlight that the ways the mother guides how boys and girls are raised evidence the discursive process of identity configuration, which is oriented by quite traditional pedagogical models (such as 'girls are not allowed to play') and concepts that seem to spread a non-investment in sports feminization.
\end{abstract}

Keywords: Body Practices. Gender. Family.

\section{¿Cuál es el precio de ser niña? Implicaciones de las expectativas corporales}

\section{Resumen}

El presente artículo, inspirado en el campo de los estudios de género, analiza las estrategias dirigidas para la normalización y el control de las expectativas corporales deportivas de niñas y de niños. La propuesta en este artículo es la de responder a la siguiente cuestión: ¿Quién y qué se habla sobre las expectativas corporales deportivas de las niñas y de los niños? Para esta discusión, seleccione una materia publicada en la revista Pais \& Filhos. En este momento de análisis, destacó que los modos como la madre orienta la educación de niños y niñas evidencian el proceso discursivo de configuración de identidades pautado por modelos pedagógicos bastante tradicionales (niña no puede jugar) y por conceptos que parecen ser propagadores de desinversión de la feminización deportiva.

Palabras clave: Prácticas Corporales. Prácticas Deportivas. Género. Familia.

\section{Referências}

BAUMAN, Z. Identidade: entrevista a Benedetto Vecchi/ Zygmunt Bauman. Rio de Janeiro: Jorge Zahar, 2005

BEAUVOIR, S. O segundo sexo. Rio de Janeiro: Nova Fronteira, 1980.

BORDO, S. Organized Sex. Cross Currents. The Flight to Objectivity: Essays on Cartesianism and Culture. New York: SUNY Press, v. 30, n. 3, 1980.

BUTLER, J. Problemas de gênero. São Paulo: Civilização Brasileira, 1999.

Pensar a Prática, Goiânia, v. 15, n. 3, p. 551-820, jul./set. 2012 
DAOILO, J. A cultura do corpo. São Paulo: Papirus, 2004.

DEL PRIORE, M. História das mulheres no Brasil. São Paulo: Contexto, 1997.

FONSECA, C. Família, fofoca e honra. Porto Alegre: Editora Universitária UFRGS, 2000.

GOELLNER, S. V. Bela, maternal e feminina: imagens da mulher na Revista Educação Physica. Ijuí: Unijuí, 2003.

, S. Mulher e esporte no Brasil: entre incentivos e interdições elas fazem história. Pensar a Prática, Goiânia, v. 8. n. 1, (2005).

GOFFMAN, E. Estigma (Notas sobre a manipulação da identidade deteriorada). Rio de Janeiro; Guanabara.

YOSHIMURA, K. Os Deficientes Também São Gente. EUA: Correio da UNESCO, 1988.

LARROSA, J. Danças, piruetas e mascaradas. Belo Horizonte: Autêntica, 2001.

LOURO, G. L. Gênero, sexualidade e educação: uma perspectiva pós-estruturalista. Petrópolis: Vozes, 1997.

MEYER, D. Gênero e educação: teoria e política. In: LOURO, G. L.; NECKEL, J. F.; GOELLNER, S. V. (org.). Corpo, gênero e sexualidade: um debate contemporâneo na educação. Petrópolis: Vozes, 2004.

MIRA, M. C. O leitor e a banca de revistas: a segmentação da cultura no Século XX. São Paulo: Olho D’Água/FAPESP, 2001.

RAGO, M. Do cabaré ao lar: a utopia da cidade disciplinar - Brasil 1890-1930. São Paulo: Paz e Terra, 2000.

SILVA, T. T. Documentos de identidade: uma introdução às teorias do currículo. Belo Horizonte: Autêntica, 2002.

SOARES, C. Imagens da educação no corpo. Campinas: Autores Associados, 2002. 
PAIS \& FILHOS. São Paulo: Bloch e Manchete, anos 1-42. (Coleção).

Recebido em: 13/06/2011

Revisado em: 20/11/2011

Aprovado em: 07/04/2012

Endereço para correspondência

simone@unijui.edu.br

Maria Simone Schwengber

Universidade Regional do Noroeste do Estado do Rio Grande do Sul.

Rua São francisco, 501

São Geraldo

98700-000 - Ijui, RS - Brasil - Caixa-postal: 301 